\title{
Primary musculoskeletal hydatid cyst of the thigh: Diagnostic and curative challenge for an unusual localization
}

\author{
Nicolas Argy MD ${ }^{1}$, Ahmed Abou Bacar MD ${ }^{1}$, Cyril Boeri MD², Caroline Lohmann MD ${ }^{1}$, Alexander W Pfaff PhD ${ }^{1}$, \\ Yves Hansmann MD PhD ${ }^{3}$, Daniel Christmann MD PhD', Ermanno Candolfi MD PhD ${ }^{1}$, Nicolas Lefebvre $\mathrm{MD}^{3}$
}

\begin{abstract}
N Argy, A Abou Bacar, C Boeri, et al. Primary musculoskeletal hydatid cyst of the thigh: Diagnostic and curative challenge for an unusual localization. Can J Infect Dis Med Microbiol 2013;24(3):e99-e101.

Primary muscular echinococcosis is an uncommon localization of hydatid cysts. The nonspecific clinical presentation and possible posttherapeutic complications lead to problems for the diagnosis of this infection and the support of the patient. The authors describe an unusual case of double hydatid cyst of the vastus intermedius muscle. After a precise preoperative evaluation based on clinical, radiological and biological examinations, a surgical excision by pericystectomy combined with perioperative chemotherapy enabled the authors to treat the patient and to prevent postoperative complications. The diagnostic tools and the treatment of this particular type of echinococcosis are discussed.
\end{abstract}

Key Words: Hydatid cyst; Muscular echinococcosis; Pericystectomy; Perioperative chemotherapy

$\mathrm{H}$ ydatid disease is a cosmopolitan anthropozoonosis more prevalent in livestock-rearing countries (1). Resulting from the larval form of the dog tapeworm Echinococcus granulosus, hydatid cysts (HC) are most frequently found in the liver (75\%) and lungs (15\%) (2). Primary muscular hydatidosis is uncommon even in endemic regions ( $1 \%$ to $4 \%)(2,3)$. Because of an asymptomatic evolution, the diagnosis of musculoskeletal hydatidosis remains difficult and the therapeutic management is often complicated. In the present article, we report a case involving double primary muscular $\mathrm{HC}$ of the thigh, with particular emphasis on the diagnostic and therapeutic challenges.

\section{CASE PRESENTATION}

A 60-year-old Turkish woman who had lived in France for 20 years presented with swelling of the right thigh that had been increasing in volume for six months and had become progessively more painful. The patient had a history of arterial hypertension, gonarthrosis and obesity. The physical examination revealed no deterioration of the clinical condition, no fever and no pulmonary, digestive or cutaneous signs. Due to the patient's obesity, the size of the lower limb prevented good clinical examination of the soft tissue mass. The laboratory tests showed no abnormalities.

Ultrasound examination (UE) of the thigh revealed the presence of two cysts, each $10 \mathrm{~cm}$ in diameter. Without associated inflammatory syndrome, these cysts evoked suspicion of $\mathrm{HC}$ in this patient who originating from an area in which echinococcosis is endemic. This hypothesis was validated a few days later by serological testing with a positive ELISA test confirmed by Western blot. In the extended assessment, a thoraco-abdomino-pelvic computed tomography scan enabled visualization of the muscular mass, showed no

\author{
Un kyste hydatique musculosquelettique primaire \\ de la cuisse : des problèmes diagnostiques et \\ curatifs à un foyer inhabituel
}

L'échinococcose musculaire primaire est un foyer inhabituel des kystes hydatiques. La présentation clinique non spécifique et les complications post-thérapeutiques éventuelles peuvent s'associer à des difficultés à diagnostiquer cette infection et à soutenir le patient. Les auteurs décrivent un cas inhabituel de double kyste hydatique du muscle vaste intermédiaire. Après une évaluation préopératoire détaillée fondée sur des examens clinique, radiologique et biologique, les auteurs ont traité le patient en procédant à une excision chirurgicale par périkystectomie conjuguée à une chimiothérapie périopératoire, ce qui a permis d'éviter les complications postopératoires. Ils présentent également les outils diagnostiques et le traitement de ce type d'échinococcose.

${ }^{1}$ Institut de parasitologie et de pathologie tropicale de Strasbourg, centre hospitalo-universitaire de Strasbourg, Strasbourg; ${ }^{2}$ Centre de traumatologie et d'orthopédie, hôpital d'Illkirch, Illkirch; ${ }^{3}$ Service des maladies infectieuses, centre hospitalo-universitaire de Strasbourg, Strasbourg, France Correspondence: Dr Nicolas Argy, Institut de parasitologie et de pathologie tropicale, centre hospitalo-universitaire de Strasbourg,

3, rue Koeberlé, 67000 Strasbourg, France. Telephone 33-0-3-68-85-3700, fax 33-0-3-68-85-3809, e-mail nicolas.argy@gmail.com 


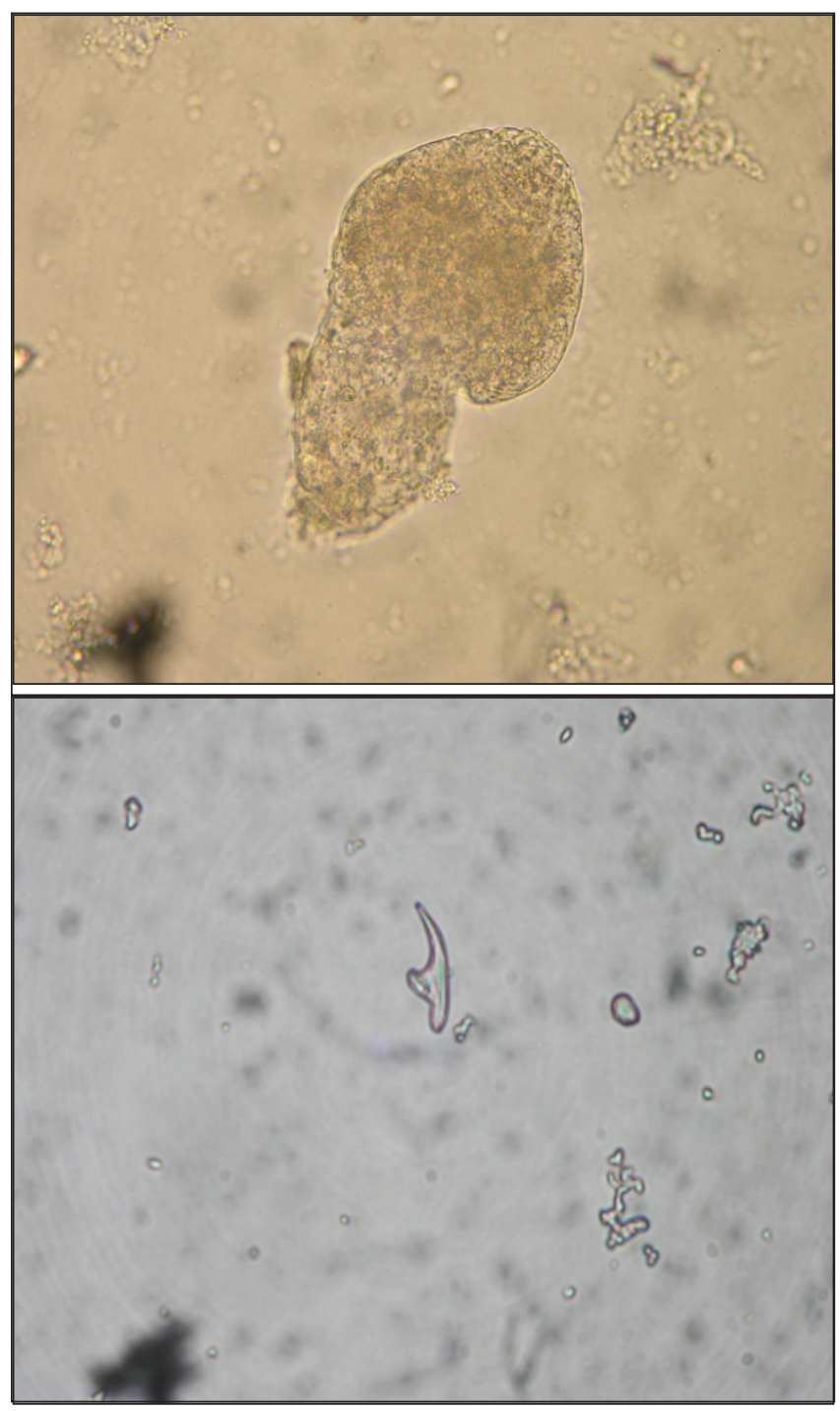

Figure 2) A Protoscolex and B hook of Echinococcus granulosus contained in the hydatid cyst

The postoperative course of the patient was favourable. However, three weeks later, the patient complained of a slight pain on the back of the right thigh. Despite the absence of hypereosinophilia, pulmonary and cutaneous signs, a possible relapse was discussed. Albendazole was continued ( $400 \mathrm{mg}$ twice per day) for two months and radiological controls were performed. UE revealed a heterogeneous aspect of the muscular tissue and magnetic resonance imaging confirmed a relapse, with persistence of a cystic area composed of two multilobed cysts $(7 \mathrm{~cm} \times 3.5 \mathrm{~cm}$ in diameter) (Figure 3$)$ in the middle one-third of the vastus intermedius muscle. Drainage with the percutaneous aspiration and instillation reaspiration (PAIR) technique was performed and combined with $400 \mathrm{mg}$ of albendazole twice per day. The PAIR technique was repeated seven weeks after the first surgery, but was obviously not successful. The drainage was difficult because of viscous contents and cystic subdivision. Finally, nine months after the first operation, a second pericystectomy was performed (Figure 4). Albendazole treatment was sustained until surgery and for three months thereafter. Parasitological examination of the cystic mass once again confirmed $\mathrm{HC}$.

The postoperative course was characterized by clinical improvement, absence of cystic formation on repeated UE and a negative ELISA test several months after the surgery.

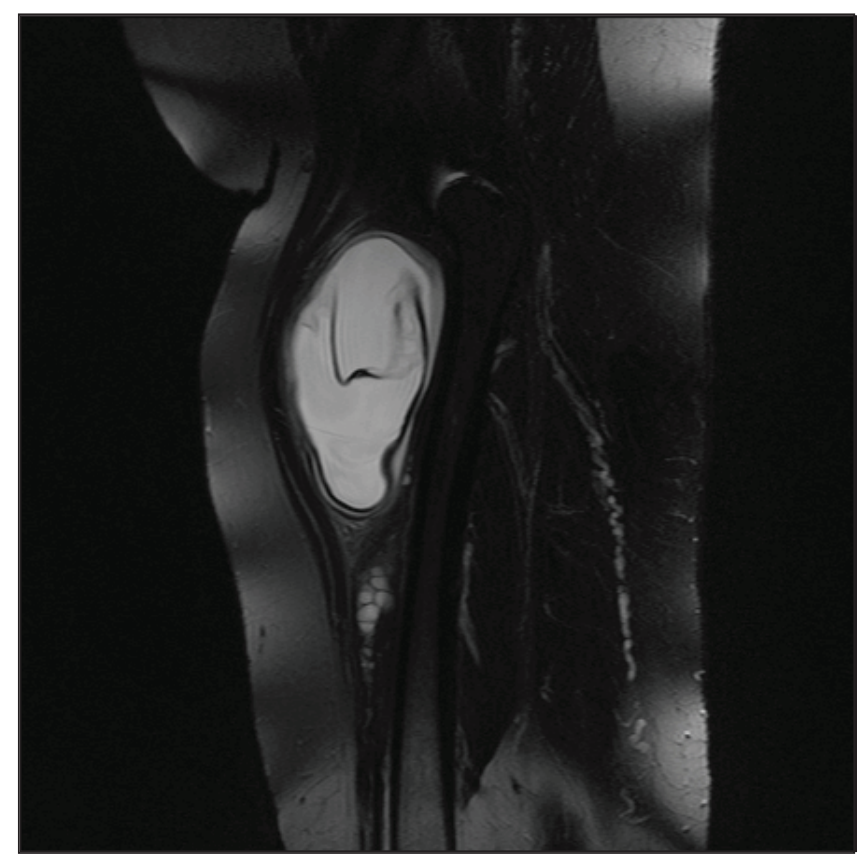

Figure 3) Muscular hydatid cyst $(7 \mathrm{~cm} \times 3.5 \mathrm{~cm})$ with proliferative membrane presenting the 'water lily sign' on magnetic resonance imaging examination

\section{DISCUSSION}

Echinococcosis is a cosmopolitan anthropozoonosis transmitted by canid species. Humans are a dead-end host infected via the ingestion of eggs in contaminated environments. The filtration capacity of the liver and lungs facilitates larval sequestration; however, they can reach many other organs (4).

Primary muscular $\mathrm{HC}$ is a rare localization (2,3). Echinococcus strains do not present muscular tropism and the muscle is not a favourable environment for larval growth $(2,4-8)$. However, several cases have been reported in upper $(1,2,11)$ and lower proximal muscles $(3,4,6-10,12,13)$. To our knowledge, no reports of multiple $\mathrm{HC}$ in the vastus intermedius muscle have been documented.

Muscular $\mathrm{HC}$ is an insidious infection with no specific symptoms. Possible differential diagnoses include lipoma, calcified hematoma, cold abscess or soft tissue tumour. Musculoskeletal echinococcosis should always be suspected in patients originating from endemic regions $(1,5,6,14)$.

Preoperative diagnosis of muscular $\mathrm{HC}$ is fundamental. Biological diagnosis is mainly based on serological tests. Positive in $90 \%$ of liver hydatidosis cases, the serological techniques (ELISA or indirect hemagglutination) are frequently negative for other localizations (1). In fact, $<30 \%$ of serologies were positive in a cohort of patients with musculoskeletal echinococcosis (1). In our case, the positive ELISA test and Western blot enabled us to confirm the diagnosis. However, the only biological tests that enable a definitive diagnosis are parasitological and pathological examinations of the cyst.

UE can guide the diagnosis with a sensitivity of $100 \%$ in typical cases. Computed tomography provides better information about number, size, site and structure of cysts, as well as their relationship with the surrounding tissues $(4,6)$. However, in atypical presentations of $\mathrm{HC}$, magnetic resonance imaging is the radiological test of choice because of its heightened analytic resolution enabling visualization of multivesicular cysts and the low-intensity rim known as 'rim sign' (1,2,5-7). In our case, this imaging technique was used to diagnose a relapse and revealed the presence of the detached germinative membrane known as the 'water-lily sign', which is pathognomonic of $\operatorname{HC}(1,2,5,6,15)$.

Pericystectomy constitutes the best surgical approach for the treatment of muscular HC in cases of small superficial cysts or cysts not adhering to vascular nerve $(1,2,4-6,8)$. In our case, this surgical approach was chosen to extract the totality of the $\mathrm{HC}$ but, 


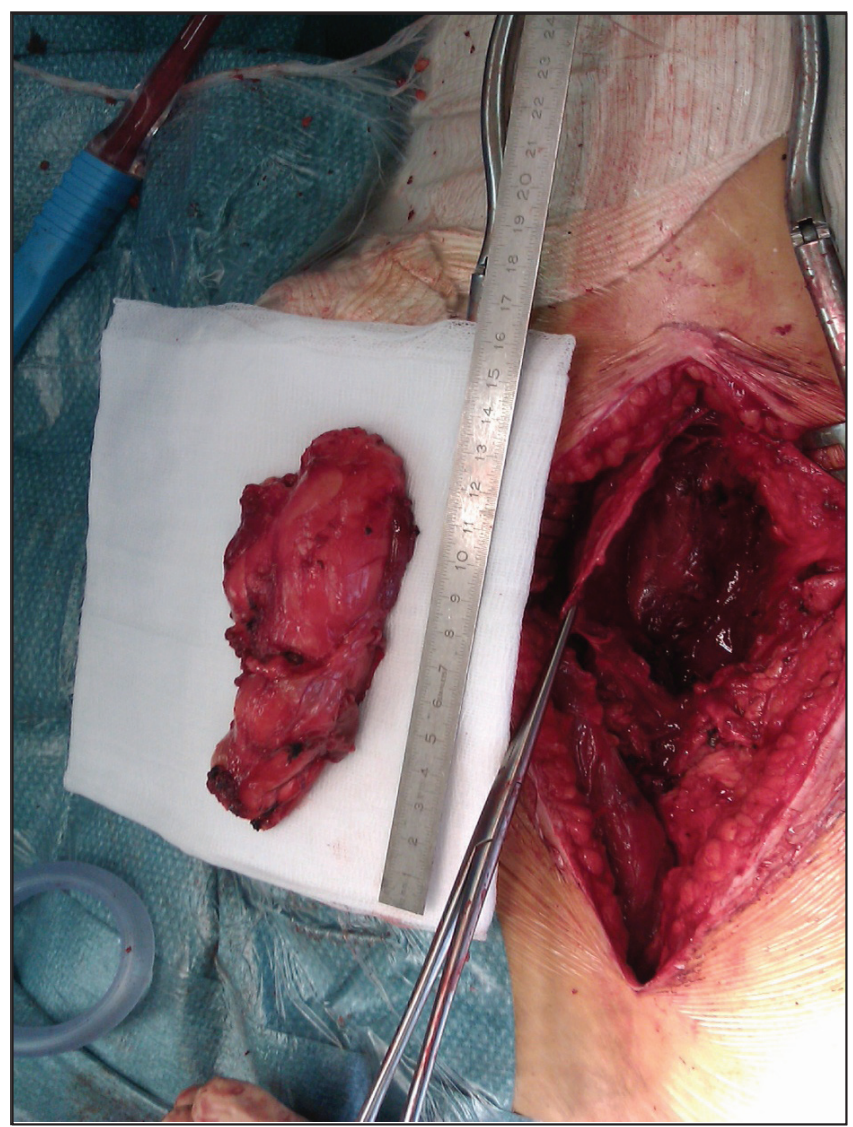

Figure 4) Muscular hydatid cyst removed by pericystectomy after the second operation

\section{REFERENCES}

1. Gougoulias NE, Varitimidis SE, Bargiotas KA, Dovas TN, Karydakis G, Dailiana ZH. Skeletal muscle hydatid cysts presenting as soft tissue masses. Hippokratia 2010;14:126-30.

2. Hamdi MF, Touati B, Abid A. Primary hydatid cyst of the biceps femoris. Musculoskelet Surg 2010;94:59-61.

3. Vicidomini S, Cancrini G, Gabrielli S, Naspetti R, Bartoloni A. Muscular cystic hydatidosis: Case report. BMC Infect Dis 2007;7:23.

4. Acar A, Rodop O, Yenilmez E, Baylan O, Oncül O. Case report: primary localization of a hydatid cyst in the adductor Brevis muscle. Turkiye Parazitol Derg 2009;33:174-6.

5. Mseddi M, Mtouami M, Dahmene J, et al. Hydatid cysts in muscles: Eleven cases. Rev Chir Orthop Reparatrice Appart Mot 2005; $91: 267-71$.

6. Jerbi Omezzine S, Abid F, Mnif H, et al. Primary hydatid disease of the thigh. A rare location. Orthop Traumatol Surg Res 2010;96:105-08

7. Kazakos CJ, Galanis VG, Verettas DAJ, Polychronidis A, Simopoulos C. Primary hydatid disease in femoral muscles. J Int Med Res 2005;33:703-6.

8. Madhar M, Aitsoultana A, Chafik R, Elhaoury H, Saidi H, Fikry T. Primary hydatid cyst of the thigh: On seven cases. Musculoskelet Surg 2013;97:77-9. unfortunately, failed to do so in the first procedure. Use of preoperative hypertonic saline solution is mandatory to prevent the dissemination of protoscoleces $(6,8)$.

The PAIR technique can be useful in inoperable cases and may also decrease peri- and postoperative complications $(1,2)$. Given the surgical history of our patient and the size of the cysts, we used the PAIR method as a first-line treatment. However, PAIR was not completely successful, revealing its limits in atypical HC.

Chemotherapy is controversial and there is no consensus supporting its use in musculoskeletal echinococcosis. Some authors recommend the use of albendazole $(400 \mathrm{mg} /$ day $)$ in peri- or postoperative treatment (1). Others claim that medical treatment has little place in muscular $\mathrm{HC}$ management and that its use should be limited, possibly associated with praziquantel, to complicated cases $(5,6,8)$. For the management of our patient, we decided to use albendazole in association with surgery. In fact, starting the medical treatment before excision yields a high serum level which reduces intracystic pressure, while the postoperative treatment is aimed at stopping parasitic dissemination. The duration of treatment should be based on clinical, biological and radiological improvement.

\section{SUMMARY}

Primary muscular $\mathrm{HC}$ is rare. To prevent accidental rupture of $\mathrm{HC}$ during inappropriate surgery, an adequate preoperative diagnosis is essential. This diagnosis requires a multidisciplinary approach including clinical, radiological and biological examinations. Surgical procedure combined with albendazole appears to be the optimal curative course of action.

ACKNOWLEDGEMENTS: The authors thank Dr Boeri and Dr Lohmann for their high-quality photographs.

DISCLOSURES: The authors have no financial disclosures or conflicts of interest to declare.

9. Ozkoç G, Arkpmar S, Ali Hersekli M, Ozalay M, Tandogan R. Primary hydatid disease of the quadriceps muscle: A rare localization. Arch Orthop Trauma Surg 2003;123:314-6.

10. Keskin D, Ezirmik N, Karsan O, Gürsan N. Primary hydatidosis of the gracilis muscle in a girl. J Int Med Res 2002;30:449-51.

11. Sogüt $O$, Ozgönül A, Bitiren M, Köse R, Cece H. Primary hydatid cyst in the deltoid muscle: An unusual localization. Int J Infect Dis 2010;14(Suppl 3):e347-8

12. Manouras A, Lagoudianakis EE, Markogiannakis $\mathrm{H}$, et al. Primary hydatidosis of the gluteus muscles: Report of three cases. Ir J Med Sci 2009;178:359-62.

13. Bedioui H, Nouira K, Daghfous A, et al. Primary hydatid cyst of the psoas muscle: Description of 9 cases in Tunisia and review of the literature. Med Trop (Mars) 2008;68:261-6.

14. Notarnicola A, Moretti L, Panella A, et al. Case report of a primary multiloculate muscular cystic hydatidosis. Chir Organi Mov 2009;93:79-83

15. Comert RB, Aydingoz U, Ucaner A, Arikan M. Water-lily sign on MR imaging of primary intramuscular hydatidosis of sartorius muscle. Skeletal Radiol 2003;32:420-23. 


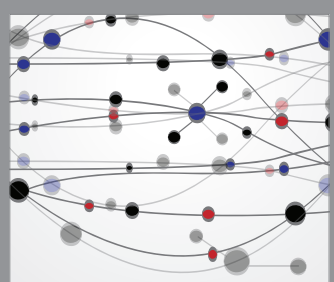

The Scientific World Journal
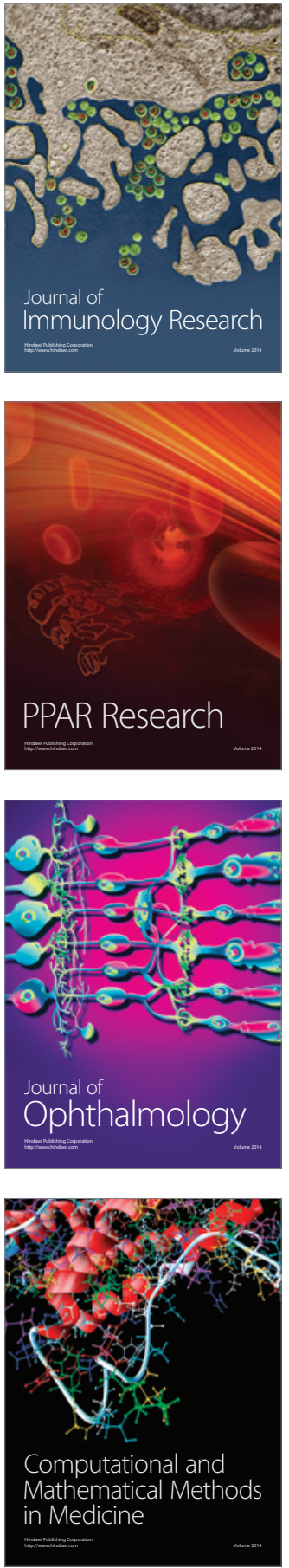

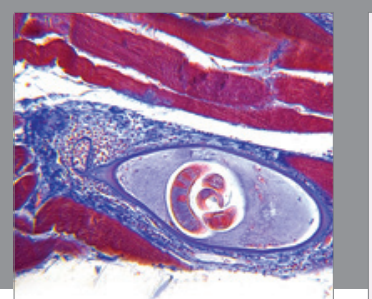

Gastroenterology Research and Practice

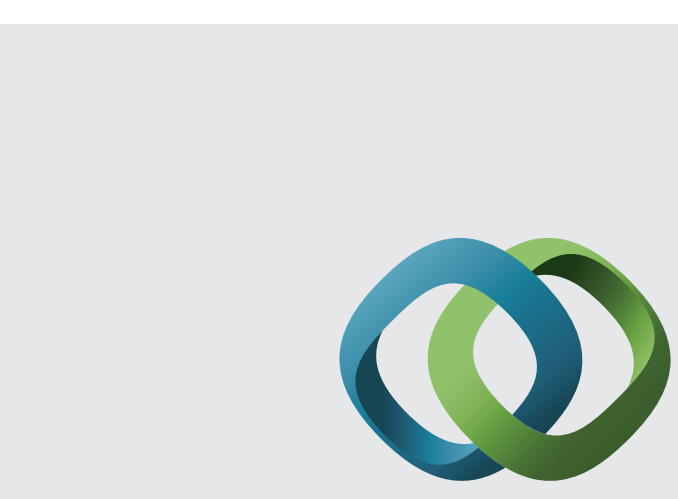

\section{Hindawi}

Submit your manuscripts at

http://www.hindawi.com
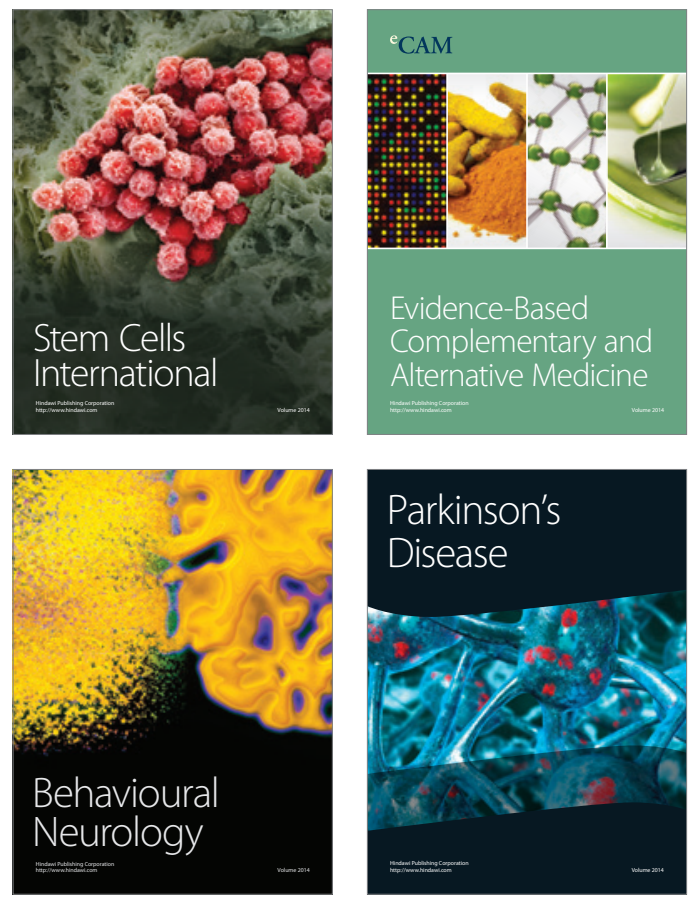
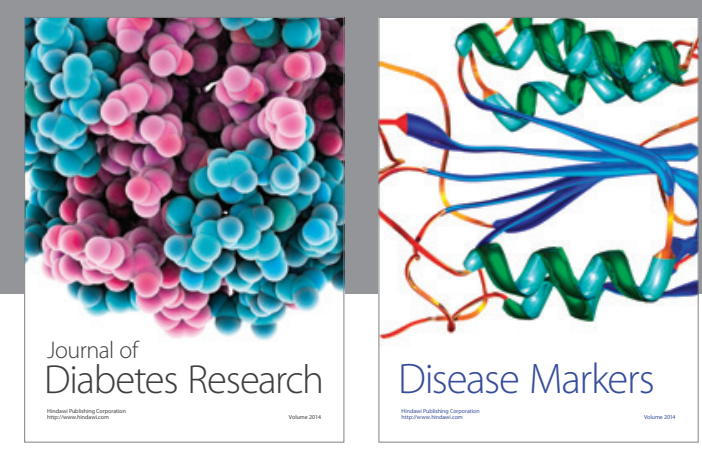

Disease Markers
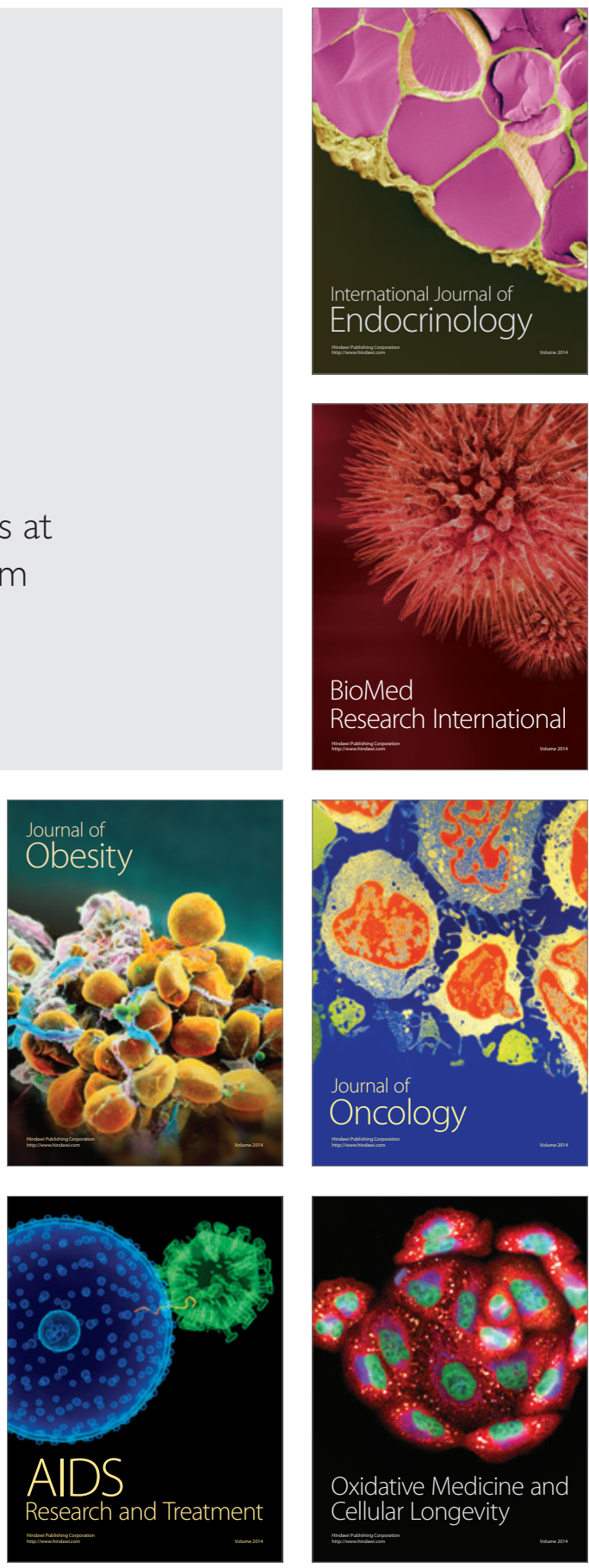